\title{
Determination of Skeletal Age in Nigerian Children: Applicalibility of the Greulich and Pyle Atlas
}

\author{
* Udoaka, A. I, *Didia, B. C and *Madueke, S C. \\ *Department of Anatomy, College of Health Sciences, \\ University of Port Harcourt, Port Harcourt \\ alabaudoaka@yahoo.com
}

\begin{abstract}
The skeletal age (bone age) is the average age at which a particular stage of bone maturation is achieved. The Greulich and Pyle standard is the commonest method used to assess the skeletal age using the hand and wrist radiograph throughout the world. This atlas was composed solely from Caucasian children using the orderly sequence of carpal ossification. Several authors have faulted this at/as for not being suitable for other races.The aim of this study is to determine if the Greulich and Pyle At/as is applicable to Nigerian children when compared to their chronological ages. The total number of 78 normal radiographs of the hand and wrist of Nigerian children were used for this study from several hospitals. These radiographs were compared with the atlas and their skeletal ages noted from the atlas. The child's chronological age in each was also recorded. The result shows a mean increase of two months in the skeletal ages of the Nigerian children compared to the at/as. This difference however was not significant.
\end{abstract}

Keywords: Skeletal Age, Greulich and Pyle Atlas, Ossification, Chronological Age.

\section{INTRODUCTION}

The degree of maturation of a child's bones, as he grows from the foetal life throughout childhood, puberty and finishes growth as a young adult can be viewed using radiographs. The bones of the skeleton progressively change in size, shape and opacity till maturity. The skeletal age (bone age) is therefore defined as the average age at which children reach a particular stage of bone maturation. The Greulich and Pyle standard Atlas is a method of evaluating hand and wrist bone age. This atlas was composed solely from Caucasian children in the 1930s ${ }^{1}$. This method has the advantage of simplicity and availability of multiple ossification centres for the evaluation of bone maturity. It is presently the most commonly used method for skeletal bone assessment throughout the world.

The skeleton especially that of the hand and wrist has the following advantages in assessing the development of the child; these include readily visible changes associated with progressive maturity on the radiographs, occurrence of ossification in orderly sequence. This sequence of chondrification and subsequence ossification was first described in $1929^{2}$. Ossification of the carpal bones in healthy children moves in an anti-clockwise direction starting with Capitate-Hamate- Triquetrum-LunateTrapezium-Trapezoid and Pisiform. The Scaphoid bone though not as constant would ossify pre or post- trapezium ${ }^{3}$. This variability of the Scaphoid, being very brief, (not exceeding three months) with reference to the Trapezium and Trapezoid creates no great practical difficulty in the assessment of hand radiographs. This orderly sequence of ossification covers the entire period from birth to early adulthood and permitting direct comparison of children irrespective of differences in body sizes, this has been confirmed by more extensive studie $e^{4,5}$. These authors found a comparable regularity in the order of chondrification of the other skeletal elements of the hand and wrist as well as in the order of the appearance of their primary centres of ossification. This order of order onset of the ossification in the carpals has also been observed from studies done in Jamaica" and Kenya ${ }^{7}$ This is an exception to the rule where the ossification of the carpals occurs in a typical order as a result of childhood illness and other unfavourable environmental factors ${ }^{8}$.

The skeletal age in the Greulich and Pyle Atlas corresponds to the chronological age at which the children on which the standards were based usually attained the same degree of skeletal development. This Atlas makes it possible to relate a child's skeletal age to chronological age. The chronological age of a child before the second decade of life is often a measure of the length of time he or she has lived on earth. Skeletal age therefore is useful to the physician in forming a judgment about 
the child's health and development status. This assessment is therefore important in the diagnosis of paediatric growth disorders. The applicability of the Greulich and Pyle to different populations has been studied extensively by several authors ${ }^{9}, 10,11$. This is because of known racial, economic, physical and other differences that exist in different populations. The objective of this study therefore, is to compare the skeletal age and chronological age in Nigerians children in order to test the applicability of the Greulich and Pyle standards in this specific population.

\section{MAterials AND Methods}

Anterior-posterior radiographs of the left hand of children were employed in this. The radiographs were randomly selected from the archives of the Radiology departments of University of Port Harcourt Teaching Hospital, Port Harcourt, Nnamdi Azikiwe University Teaching Hospital,

Nnewi, The University of Nigeria Teaching Hospital, Enugu and Hopeville Orthopaedic Hospital, Woji, Port Harcourt.

The radiographs were identified to be those of indigenous Nigerians. The left hand radiographs were utilized in this study as the minor differences between the skeletal ages of the two hands are insignificant. The radiographs were viewed with a viewing box in each case to rule out fractures and other visible anthologies which had probably led to interrupted growth. The biodata was collected from the X-Ray jackets and confirmed from the records kept by the various departments. Each radiograph selected was then compared with the standard of the same sex and nearest chronological age in the atlas. Secondly, the films were then compared with adjacent standards, both older and younger than the one of the nearest chronological age. Then the standard nearest in comparison was then selected. This selection depended upon changes in the shape of the bones and on other skeletal features visible I the list of maturity indicators.

After finding the standards that resemble most closely the radiographs to be assessed, a more detailed comparison of the individual bones and epiphyses visible in them was made. The skeletal age of each radiograph was then recorded together with the child's chronological age.

Statistical analysis included frequency distribution percentages and square (x2) was used to test the level of significance.

\section{Results}

From Table 1, the mean skeletal age of the studied group was seen to be 7 years and 4 months $(7.30$ years with a standard deviation of 1.97), while the mean chronological age was 7 years and 2 months (7.20 years with a standard deviation of 0.22). this shows a mean increase of the skeletal age compare with the study group's chronological age. The skeletal age of the Nigerian children though averagely two months more than their chronological was not statistically significant $(\mathrm{x} 2=0.27 \mathrm{P}=0.05$ Not Significant). The result also shows that the skeletal bone maturity occurred much more in ages $(0-2$ years) than the chronological age giving a deficit of 2 children (in the frequency under skeletal age) moving to the next age range and the pre/early pubertal age of 12 - 14 years which also recorded a deficit of 1 child, moving to the next category. The rest of the age ranges had same frequency with only minor differences in months. Altogether $77 \%$ of the children had greater insignificant skeletal maturity.

Table 1, showing the age range, frequency of occurrence of Skeletal ages using the radiographic atlas of Greulich and Pyle and the frequency of occurrence of the Chronological ages of the children.

\begin{tabular}{|l|l|l|}
\hline \multicolumn{1}{|c|}{ Age range (years) } & \multicolumn{1}{|c|}{ Skeletal age Frequency } & \multicolumn{1}{c|}{$\begin{array}{c}\text { Chronological age } \\
\text { Frequency }\end{array}$} \\
\hline $0-2$ & 20 & 22 \\
\hline $3-5$ & 21 & 19 \\
\hline $6-6$ & 6 & 6 \\
\hline $9-11$ & 8 & 8 \\
\hline $12-14$ & 10 & 11 \\
\hline $15-17$ & 11 & 10 \\
\hline $18-20$ & 2 & 2 \\
\hline
\end{tabular}

Mean Skeletal Age .30 years; SD 1.97

Mean Chronological Age 7.20 years; SD 0.2

$X^{2}=0.27 ; P=0.05$ Not Significant Mean discrepancy between Skeletal and Chronological age is two months. 


\section{DISCUSSION}

This study has shown a mean increase of 2 months though not significant ( $p>0.05)$ in the skeletal ages of Nigerian children when compared to the group (Caucasian children) that were used to compile the Greulich and Pyle Atlas. The skeletal age (in months) was greater than the chronological age in $77 \%$ of the children.

This study corroborates a study done in 1993, 34 years after the work of Greulich and Pyle on black and white children in the same geographic area from where the atlas originated. There were minor variables noted in the African American girls who were more skeletally advanced by four to eight months compared with - the atlas for most of their growing period ${ }^{12}$. In another study of children of European descent had significantly delayed skeletal maturity when compared with those of African descent and post- pubertal European American males had significantly advanced skeletal maturity when compared with post-pubertal African American males.

The applicability of the atlas to different populations has also been investigated. A study of the atlas compared with Malawian children showed significant mean reduction in skeletal age, this was attributed to inadequate nutrition leading to skeletal delay ${ }^{14}$. This was also the conclusion from an earlier study by Fleshman ${ }^{15}$ though he was unable to show statistically significant support for this hypothesis.

The Greulich and Pyle standard, when compared with Central European children was found to be reliable and as such suitable for assessing them ${ }^{16}$. This was also corroborated by a study of Dutch children9. In another study on Taiwanse children, there was retardation of bone age when compared with the atlas before puberty followed by an increase after puberty ${ }^{11}$.

Knowledge of skeletal age in children is important and especially useful in paediatric endocrinology, orthopeadics, forensic anthropology and sports medicine. In children for whom hormonal therapy is being considered, time of initiation and duration of therapy rely on accurate assessment of skeletal age.

In conclusion, the bone age of Nigerian children, though more advances than the Greulich and Pyle standards by 2 months is not statistically significant and as a result this study finds the radiographic atlas of Greulich and Pyle suitable for assessing Nigerian children.

\section{CONCLUSION}

The mean skeletal age of Nigerian children though more than the standard in the atlas is not statistically significant, as a result the study finds the radiographic atlas of Greulich and Pyle atlas applicable to Nigerian children.

\section{ACKNOWLEDGEMENT}

The authors wish to acknowledge the heads of departments and staff of the radiology departments of various hospitals used for the study.

\section{REFERENCES}

[1] Greulich WW, Pyle SI. Radiographic atlas of skeletal development of the hand and wrist. $2^{\text {nd }}$ ed. Stanford University Press, Stanford 1999.

[2] Senior HD. The chondrification of the human hand and foot skeleton. Anat Rec 16 (15): 1435 - 42. (1956);

[3] Gray OJ, O'Rahilly R. The prenatal development of the skeleton and joints of the human hand. Am J Anat; 101: 169 - 223. (1957)

[4] Stuart HC, Pyle 51, Coroni J, Reed RB. Onsets, completions and spans of ossification in the 29 bone growth centres of the hand and wrists. Paediatr; 29 (2) 237 - 249. (1962)

[5] Strivastav A, Saraswat PK, Agarwal SK, Gupta P. A study of wrist ossification for age estimation in paediatric group in Central Rajasthan. Journal of Indian Academy of Forensic Medicine; 26(4): 132 -135. (2004)

[6] Marchall WA, Ashcroft MT, Bryan G. Skeletal maturation of the hand and wrist in Jamaican children. Hum Bio; 42: 421 - 435. (1970) 
[7] Mackay DH. Skeletal maturation in the hand: A study of development in East African children. Trans ray Soc Trop Med Hygiene; 46: 135 - 50. (1952)

[8] Garn sm, Rohmann CG, Blumenthal T. Ossification sequence polymorphism and sexual dimorphism in skeletal development. Am $J$ Phys Anthrop; 24(1): 101 - 115. (1966)

[9] Van Rigin RR, Leguin MH, Robben SGF, Hop WCJ, Van Kuijk C. Is the Guerlich and Pyle atlas still valid for Dutch Caucasian children of today? Paediatr Radiol; 31: 748-75. (2001)

[10] Koc A, Karaoglanoglu M, Erdogan M, Kosecik M, Cesur Y. Assessment of bone age. Is the Greulich and Pyle method sufficient for Turkish boys. Pediatr Int ; 43: 662 - 665. (2001)

[11] Chiang K-H, Chou AS-B, Yen P-S, Ling C-M, Lin C-C, Chang P-Y. The reliability of using the Greulich Pyle method to determine children's bone age in Taiwan. Tzu Chi Med J; 17: 417 - 420. (2005)

[12] Loder RT, Estle OT, Morrison K, Eggleston 0, Fish ON, Greenfield ML, Guire KE. Applicability of the Greulich and Pyle skeletal age standards to black and white children of today. Am J Dis Child; 147: 1329 - 33. (1993)

[13] Mora S, Boechat MI, Pletka E, Huang HK, Gilsanz Y. Skeletal age determination in children of European and African descent: Applicability of the Greulich and Pyle standards Peditrres; 50(5): 624 - 8. (2001)

[14] Lewis CP, Lavy CBO, Harrison WJ. Delay in skeletal maturity in Malawian children. $J$ Bone joint Surg; 43: 324 -330. (2002)

[15] Fleshman K. Bone age determination in a paediatric population as an indicator of nutritional status. Trop Doct; 30: 16 -18. (2000)

[16] Groell S, Lindbichler F, Riepl T, Gherra L, Roposch A, Fotter R. The reliability of bone age determination in central European children using the Greulich and Pyle method. Br J radiol, 72(857):461-464. (1999) 